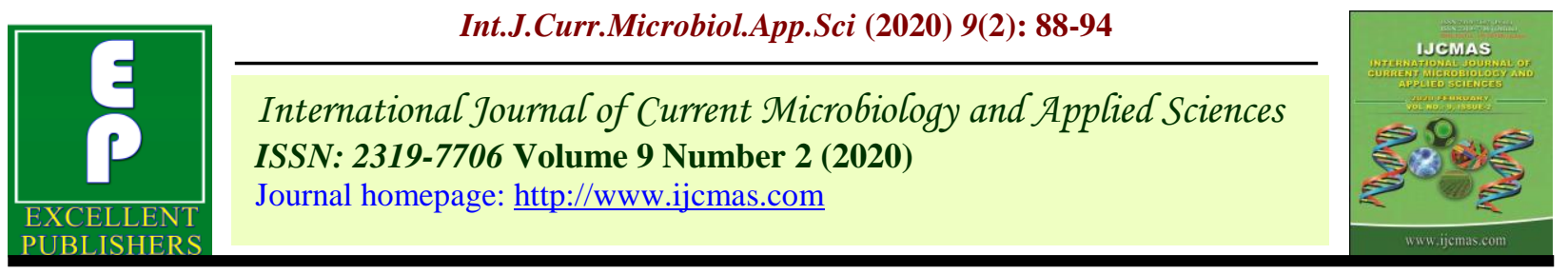

Original Research Article

https://doi.org/10.20546/ijcmas.2020.902.011

\title{
Study of Genetic Divergence in Lowland Rice Genotypes of Bihar
}

\author{
Nitesh Kushwaha ${ }^{1 *}$, Ravi Kant ${ }^{1}$, Rajesh Kumar', Nilanjaya ${ }^{1}$, Ruchika Chhaya ${ }^{2}$, \\ Naincy Sinha ${ }^{2}$, Digvijay Singh ${ }^{3}$ and Tushar Arun Mohanty ${ }^{3}$
}

Department of Plant Breeding and Genetics, Dr. Rajendra Prasad Central Agricultural University, Pusa, Samastipur, Bihar, India

*Corresponding author

\section{A B S T R A C T}

\begin{tabular}{|l|}
\hline Ke y w o r d s \\
Genetic divergence, \\
Lowland rice, \\
Genotypes, \\
Tocher's method \\
\hline Article Info \\
\hline $\begin{array}{l}\text { Accepted: } \\
\text { 05 January } 2020 \\
\text { Available Online: } \\
\text { 10 February } 2020\end{array}$ \\
\hline
\end{tabular}

The present experimental work was carried out at Rice Breeding Section, Pusa, Samastipur, with twenty-two lowland genotypes which were shown in R.B.D. style and were analysed for genetic divergence with the help of Mahalanobis's $\mathrm{D}^{2}$ statistics.Twentytwo genotypes of rice were grouped into six clusters using Tocher's method. The cluster I consists of maximum number of genotypes forming the largest cluster followed by cluster VI having three genotypes. The intra cluster distance ranged from 0.00 to 84.45. The inter cluster distance ranged from 52. to 282.49.Thehighest intra cluster distance was observed in cluster VI (84.85) followed by Cluster I (67.75). Maximum inter cluster distance was observed between cluster III and Cluster IV followed by cluster III and cluster IV. Per cent contribution of 15 characters and towards total genetic divergence was found maximum for 1000 grain weight (35.5 per cent) followed by days to flowering (22.08 per cent), grain length (17.32 per cent). It was observed that 1000 grain weight ranked $1^{\text {st }}$ maximum times (82) followed by days to flowering (51), grain length (40), plant height (36). The genotype in cluster III and cluster IV due to maximum inter cluster distance between them, exhibited high degree of genetic diversity and thus may be utilized in future for heterosis breeding programme for getting high yielding recombinants.

\section{Introduction}

Rice (Oryza sativa L.) may be originated at least 130 million years ago and dispersed all around the world with separation of different continent from the single land mass that existed. It is one of the most important food crops of the world particularly Asian countries where it is the staple food. The estimated world rice production for the year $2019-20$ is 496.67 million metric tons (USDA, 2020). It is produced in wide range of locations and under different climatic conditions. As it grows in variable climatic condition and having such an extended geographical distribution through out the world it is the crop with maximum germplasm diversity. As the consequence of great geographical distribution and extending its boundaries to various climatic conditions it faces several form abiotic stresses occurring in those environment and flooding being of those. Therefore, study of the diversity of rice in low lying flooded area is of prime 
importance for the development of new varieties, to sustain the rice production and improve the socioeconomic status of people living in these areas. Genetic divergence among the genotypes plays an important role in selection of parents having wider variability for different traits (Nayak et al., 2004) and it also helps in the development of superior recombinants (Manonmani and Khan, 2003b). Genetic diversity analysis is done with help of $\mathrm{D}^{2}$ statistics developed by P. C. Mahalanobis. Genetic divergence analysis evaluates the genetical distance among the selected genotypes and shows the relative contribution of specific traits towards the total divergence (Iftekharuddaulae et al., 2002).

\section{Materials and Methods}

The present research work was conducted at Rice Breeding Section, Pusa Farm, Dr. Rajendra Prasad Central Agricultural
University, Pusa, Samastipur, Bihar during kharif 2019. Total of twenty-two lowland rice(table 1) were investigated, which were sown in Randomized Block Design fashion at standard spacing of $15 \times 20 \mathrm{~cm}$ in three replications. All the recommended packages of practices were followed during the growth period. Observations for fifteen characters were recorded viz., grain length $(\mathrm{mm})$, grain width (mm), kernel length (mm), days to $50 \%$ flowering, plant height $(\mathrm{cm})$, root volume $\left(\mathrm{mm}^{3}\right)$, panicle length of main axis` $(\mathrm{cm})$, leaf length $(\mathrm{cm})$, leaf width $(\mathrm{cm})$, no. of panicle, days to maturity, stem thickness (mm), 1000 grain weight, kernel width(mm), grain yield per plant $(\mathrm{g})$. Various parameters of genetic diversity like clustering pattern of various genotypes, mean intra and inter-cluster distances among the different clusters, cluster mean, contribution of individual character to divergence and dendrogram of the clustering pattern were analysed using the data recorded for the fifteen characters.

\section{List of genotypes}

\begin{tabular}{|l|l|l|l|l|l|}
\hline $\mathbf{1}$ & SANTOSH & $\mathbf{9}$ & VAIDEHI & $\mathbf{1 7}$ & BRASALI \\
\hline $\mathbf{2}$ & KANAK & 10 & JANAKI & 18 & MEGHNAD \\
\hline $\mathbf{3}$ & RADHA & 11 & BAROGAR & 19 & SILHAT \\
\hline $\mathbf{4}$ & PANKAJ & 12 & MADHUKAR & 20 & SHYAMALA \\
\hline $\mathbf{5}$ & SATYAM & 13 & SINGHARA & 21 & BPT-5204-SUB 1 \\
\hline $\mathbf{6}$ & RAJSHREE & 14 & UJALA DHUSARISA & 22 & KISHORI \\
\hline $\mathbf{7}$ & SWARNA & 15 & SAGAR SAMBA & & \\
\hline $\mathbf{8}$ & SUDHA & 16 & JAGANNATH BALLAVA & & \\
\hline & & & & & \\
\hline
\end{tabular}

\section{Results and Discussion}

Genetic diversity is the most important tool in the hands of the plant breeder in choosing the right type of parents for hybridization program. The divergence can be studied by technique using $\mathrm{D}^{2}$ statistics developed by
Mahalanobis (1936). This is considered as the most effective method for qualifying the degree of genetic diversity among the genotypes included in the study. The present investigation aimed to estimate the magnitude of genetic divergence present in the 22 rice genotypes and to identify the diverse 
genotypes for future utilization breeding program.

In the present investigation the genotypes were grouped into 6 clusters (table 1, fig. 1) on the basis of $\mathrm{D}^{2}$ matrix which was based on $\mathrm{D}^{2}$ values and Ward minimum variance. Cluster I comprised of maximum number of genotypes (15) including check Swarna followed by Cluster VI which included 3 genotypes and Cluster II, III, IV and V comprised of 1 genotype each. Clustering based on the $\mathrm{D}^{2}$ distances was done by Shivani et al., (2018), Kumari et al., (2018) and Guru et al., (2017). The inter cluster distance (Table 2) ranged from 52.38 to 282.49. The highest intra cluster distance (Table 2) was observed in cluster VI (84.85) followed by Cluster I (67.75). Cluster I, III, $\mathrm{IV}$ and $\mathrm{V}$ showed intra cluster distance of 0.00 . Maximum inter cluster distance was observed between cluster III and Cluster IV followed by cluster III and cluster IV. Minimum inter cluster distance was observed between cluster II and cluster IV followed by cluster II and cluster V, indicating that the genotypes in the clusters were closely related. Similar divergence estimation based on $\mathrm{D}^{2}$ distances was done by Shivani et al., (2018) and Kumari et al., (2018).

Table.1 Clustering pattern of twenty-two genotypes of rice on the basis of $\mathrm{D}^{2}$ statistics

\begin{tabular}{|c|c|l|}
\hline $\begin{array}{c}\text { Cluster } \\
\text { No. }\end{array}$ & $\begin{array}{c}\text { No. of } \\
\text { genotypes } \\
\text { within cluster }\end{array}$ & \multicolumn{1}{|c|}{ Genotypes in cluster } \\
\hline I & 15 & $\begin{array}{l}\text { SUDHA, VAIDEHI, SILHAT, MADHUKAR, UJALA } \\
\text { DHUSARIA, JANAKI, MEGHNAD, RADHA, SANTOSH, } \\
\text { KANAK, SATYAM, SWARNA, SAGAR SAMBA, RAJSHREE, } \\
\text { BAROGAR, }\end{array}$ \\
\hline II & 1 & PANKAJ \\
\hline III & 1 & SHYAMALA \\
\hline IV & 1 & BPT-5204-SUB-1 \\
\hline $\mathbf{V}$ & 1 & KISHORI \\
\hline VI & 3 & SINGHARA, JAGANNATH BALLAVA, BRASALI \\
\hline
\end{tabular}


Table.2 Mean intra and inter cluster distance $\left(\mathrm{D}^{2}\right)$ among six cluster in rice

\begin{tabular}{|c|c|c|c|c|c|c|}
\hline & Cluster I & Cluster II & Cluster III & Cluster IV & Cluster V & Cluster VI \\
\hline Cluster I & 67.75 & 99.46 & 135.34 & 187.11 & 123.42 & 189.82 \\
\hline Cluster II & & 0.00 & 196.03 & 52.38 & 52.73 & 138.25 \\
\hline Cluster III & & & 0.00 & 282.49 & 216.60 & 102.41 \\
\hline Cluster IV & & & & 0.00 & 97.38 & 141.39 \\
\hline Cluster V & & & & & 0.00 & 166.64 \\
\hline Cluster VI & & & & & 84.85 \\
\hline
\end{tabular}

Table.3 Cluster mean values of 6 clusters of different quantitative characters in 22 rice cultivars

\begin{tabular}{|c|c|c|c|c|c|c|c|c|c|c|c|c|c|c|c|}
\hline & GL & GW & KL & DFL & PLH & $\mathbf{R V}$ & PLMA & $\mathbf{L W}$ & NP & DTM & ST & TW & KW & $\mathbf{L L}$ & YLD \\
\hline Cluster I & 8.66 & 2.66 & 6.47 & 113.53 & 144.35 & 17359.51 & 23.72 & 1.23 & 16.07 & 144.56 & 4.21 & 23.55 & 2.02 & 57.97 & 25.80 \\
\hline Cluster II & 7.67 & 2.83 & 5.93 & 119.33 & 104.87 & 21833.97 & 24.57 & 1.57 & 14.00 & 142.00 & 3.73 & 16.65 & 2.00 & 46.43 & 29.74 \\
\hline Cluster III & 8.77 & 2.30 & 6.60 & 149.33 & 185.37 & 13667.28 & 23.93 & 1.30 & 18.17 & 181.67 & 4.27 & 26.55 & 1.93 & 65.83 & 20.53 \\
\hline Cluster IV & 7.17 & 1.70 & 5.07 & 125.00 & 102.07 & 20137.33 & 24.00 & 1.20 & 16.22 & 142.33 & 3.97 & 9.47 & 1.67 & 40.70 & 23.80 \\
\hline & 9.07 & 2.83 & 6.73 & & 126.30 & 20000.46 & 25.67 & & 17.53 & 149.33 & 3.93 & 13.29 & 2.08 & 50.43 & 33.17 \\
\hline Cluster VI & 7.69 & 2.34 & 5.67 & 148.56 & 179.41 & 16111.73 & 24.12 & 1.19 & 14.77 & 170.67 & 4.02 & 17.06 & 1.91 & 61.89 & 29.57 \\
\hline
\end{tabular}

G.L.= GRAIN LENGTH, GW= GRAIN WIDTH, KL= KERNEL LENGTH, DFL= DAYS TO 50\% FLOWERING, RV= ROOT VOLUME, PLMA= PANICLE LENGTH OF MAIN AXIS, LW= LEAF WIDTH, NP= NUMBER OF PANICLES, DTM= DAYS TO MATURITY, ST= STEM THICKNESS, TW=1000 GRAIN WEIGHT, KW =KERNEL WIDTH, LL= LEAF LENGTH, YLD= GRAIN YIELD PER PLANT 
Table.4 Ranking and contribution of character towards divergence

\begin{tabular}{|c|l|c|c|}
\hline S.NO. & \multicolumn{1}{|c|}{ SOURCE } & TIMES RANKED 1 & $\begin{array}{c}\text { CONTRIBUTION } \\
(\mathbf{\%})\end{array}$ \\
\hline $\mathbf{1}$ & GRAIN LENGTH $(\mathrm{mm})$ & 40 & 17.32 \\
\hline $\mathbf{2}$ & GRAIN WIDTH $(\mathrm{mm})$ & 0 & 0.00 \\
\hline $\mathbf{3}$ & KERNEL LENGTH $(\mathrm{mm})$ & 1 & 0.43 \\
\hline $\mathbf{4}$ & DAYS TO 50\% FLOWERING & 51 & 22.08 \\
\hline $\mathbf{5}$ & PLANT HIEGHT $(\mathrm{cm})$ & 36 & 15.58 \\
\hline $\mathbf{6}$ & ROOT VOLUME $\left(\mathrm{mm}^{3}\right)$ & 0 & 0.00 \\
\hline $\mathbf{7}$ & PANICLE LENGTH OF MAIN & 0 & 0.00 \\
\hline & AXIS $(\mathrm{cm})$ & 0 & 0.00 \\
\hline $\mathbf{8}$ & LEAF WIDTH $(\mathrm{cm})$ & 0 & 0.00 \\
\hline $\mathbf{9}$ & NO. OF PANICLE & 0 & 0.00 \\
\hline $\mathbf{1 0}$ & DAYS TO MATURITY & 6 & 2.60 \\
\hline $\mathbf{1 1}$ & STEM THICKNESS $(\mathrm{mm})$ & 82 & 35.50 \\
\hline $\mathbf{1 2}$ & 1000 GRAIN WEIGHT $(\mathrm{g})$ & 1 & 0.43 \\
\hline $\mathbf{1 3}$ & KERNEL WIDTH $(\mathrm{mm})$ & 5 & 2.16 \\
\hline $\mathbf{1 4}$ & LEAF LENGTH $(\mathrm{cm})$ & 9 & 3.92 \\
\hline $\mathbf{1 5}$ & GRAIN YIELD PER PLANT $(\mathrm{g})$ & & \\
\hline
\end{tabular}

Fig.1 Clustering pattern of 22 rice cultivars on the basis of $\mathrm{D}^{2}$ statistics by Tocher's method

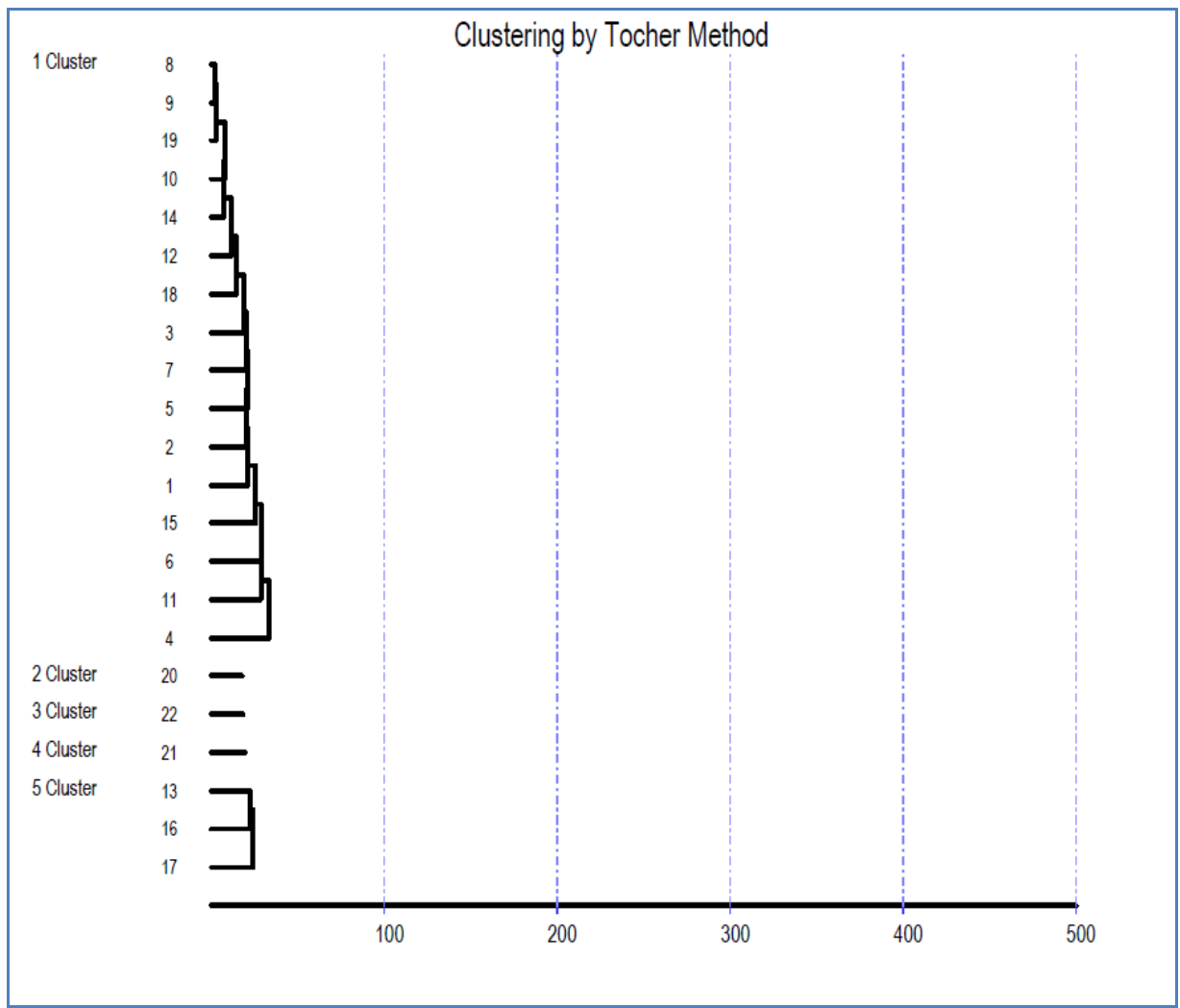


Fig.2 Intra and Inter cluster distances on the basis of $\mathrm{D}^{2}$ statistics

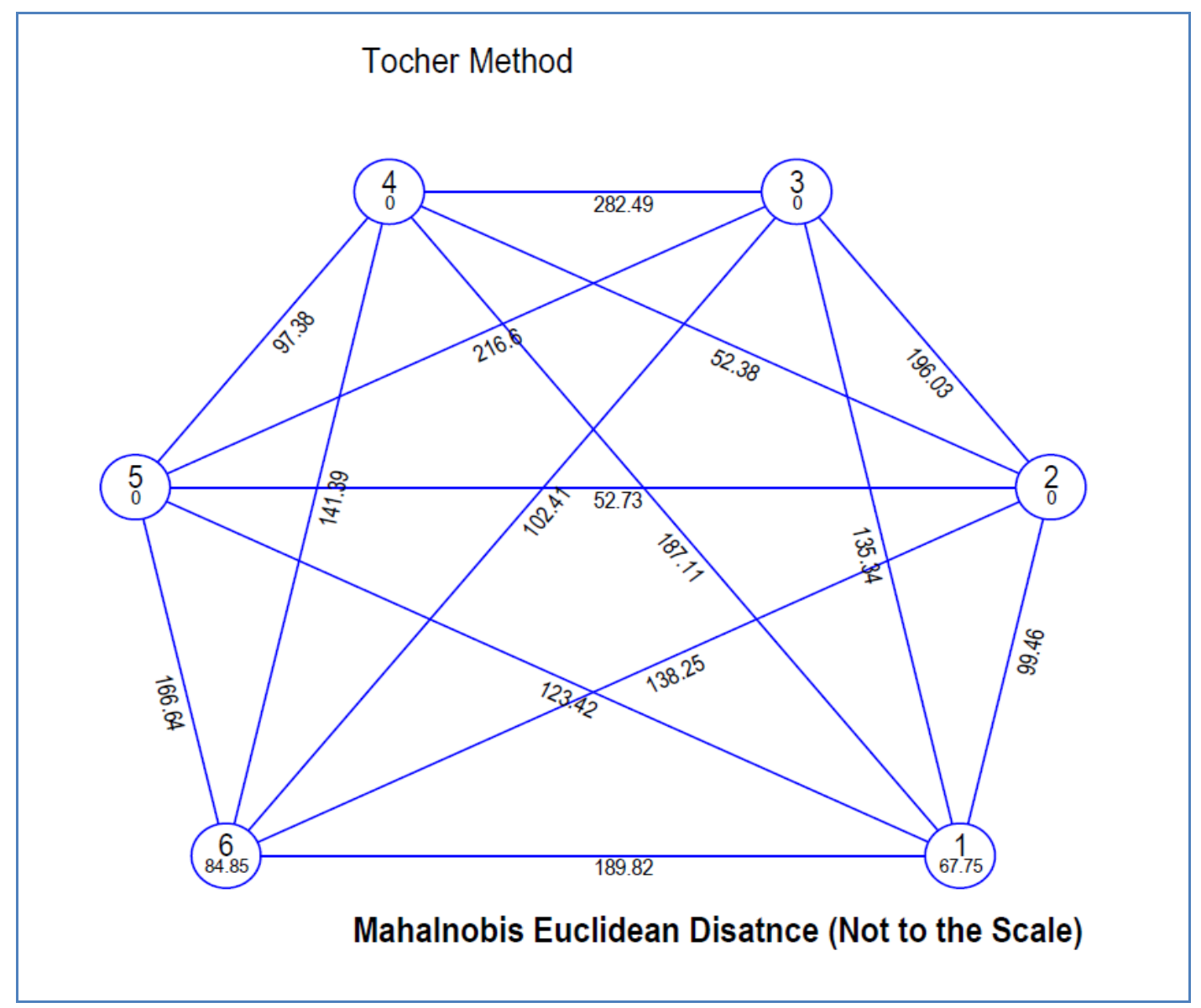

\section{Cluster mean analysis}

Cluster means (Table 3) with respect to 15 characters and 22 genotypes along with check was evaluated with help $\mathrm{D}^{2}$ values. It was evident that cluster mean for grain length was highest in cluster $\mathrm{V}$ and lowest in cluster IV while cluster mean for grain width was recorded maximum for cluster II and minimum for cluster. Kernel length recoded highest cluster mean value for cluster $\mathrm{V}$ and lowest cluster mean value for cluster $\mathrm{V}$ while cluster mean for days to 50 per cent flowering was recorded highest for cluster III and lowest for cluster I. Cluster mean performance for plant height was observed maximum for cluster III and minimum for cluster IV while maximum value for cluster mean for root volume was recorded for cluster II and minimum for cluster III. Cluster mean for panicle length of main axis was recorded highest for cluster $\mathrm{V}$ and minimum for cluster I whereas cluster mean values for leaf width was observed maximum for cluster II and cluster VI. Cluster mean values for number of panicles per plant was recorded highest for cluster and lowest for cluster II while cluster mean for days to maturity was recorded highest for cluster III and recorded minimum for cluster II. Observation of cluster mean of stem thickness showed that it was highest for cluster I and lowest for cluster II whereas cluster mean for 1000 grain weight was recorded highest for cluster III and recorded minimum cluster IV. Cluster mean for kernel width was observed maximum for cluster I and lowest for cluster IV while cluster mean for leaf length was recorded highest for 
cluster III and lowest for cluster. Cluster mean for yield per plant was observed highest for cluster $\mathrm{V}$ and minimum for cluster III. Cluster mean analysis was also done by Shivani et al., (2018), Kumari et al., (2018) and Guru et al., (2017) for selection of genotypes.

\section{Percent contribution of character towards total genetic diversity}

Per cent contribution (table 4) of 15 characters towards total genetic divergence was found maximum for 1000 grain weight followed by days to 50 per cent flowering, grain length, plant height, yield per plant, stem thickness, leaf length, kernel length and kernel width. These findings were in accordance with the finding of Shivani et al., (2018), Kumari et al., (2018) and Guru et al., (2017).Character contribution to total divergence was based on number of times character ranked first. It has been presented in the table 4. From the table it was observed that 1000 grain weight ranked $1^{\text {st }}$ maximum times followed by days to flowering and grain length (40), plant height (36),

In conclusion, twenty-two genotypes of rice were grouped into six clusters using Tocher's method. The cluster I consists of maximum number of genotypes forming the largest cluster followed by cluster VI having three genotypes and rest of the clusters i.e. II, III, IV, V were found to be mono-genotypic. The genotype in cluster III and cluster IV due to maximum inter cluster distance between them, exhibited high degree of genetic diversity and thus may be utilized in future for heterosis breeding programme for getting high yielding recombinants.

\section{References}

Guru, T., Padma, V., Reddy, V.V., Rao, P.R., Rao, D.S., Ramesh, T. and Radhakrishna, K.V. (2017). Genetic diversity analysis for yield attributing traits in rice genotypes. Res. on Crops. 18(2): 311-315.

Iftekharuddaula, K.M., Khaleda, A., Hassan, M.S., Fatema, K. and Adil Badshah 2002. Genetic divergence, character association and selection criteria in irrigated rice. Pak. J. Biol. Sci., 2: 243246.

Kumari, P., Devi, A., Dwivedi, R., Dwivedi, S., Kishor, R. and Dwivedi, D.K. (2018). Genetic divergence in indigenous and exotic rice (Oryza sativa L.) under saline-alkaline condition. Int. J. Curr. Microbiol. 7: 4546-4553.

Mahalanobis, P.C. (1936). On the generalised distance in statistics. Proceed. Nat. Instit. Sci., India, 2: 49-55.

Manonmani, S. and Fazlullah Khan, A. K. 2003b. Analysis of genetic diversity for selection of parents in rice. Oryza. 40: 54-56.

Nayak, A. R., Chaudhury, D. and Reddy, J. N. 2004. Genetic divergence in scented rice. Oryza. 41: 79-82

Shivani, Dwivedi, D.K., Husain, R., Gyanendra, K. and Khan, N.A. (2018). Genetic Divergence for Yield and other Quantitative Traits in Rice (Oryza sativa L.) Int. J. Curr. Microbiol. 7(1): 1201-1207.

USDA, 2020 United States Department of Agriculture, Washington D.C., U.S.A.

\section{How to cite this article:}

Nitesh Kushwaha, Ravi Kant, Rajesh Kumar, Nilanjaya, Ruchika Chhaya, Naincy Sinha, Digvijay Singh and Tushar Arun Mohanty. 2020. Study of Genetic Divergence in Lowland Rice Genotypes of Bihar. Int.J.Curr.Microbiol.App.Sci. 9(02): 88-94. doi: https://doi.org/10.20546/ijcmas.2020.902.011 